\title{
Cdk1 and Cdk2 activity levels determine the efficiency of replication origin firing in Xenopus
}

\author{
Liliana Krasinska ${ }^{1,4}$, Emilie Besnard ${ }^{2,4}$, \\ Emilie Cot ${ }^{1,4}$, Christiane Dohet ${ }^{1,4}$, \\ Marcel Méchali ${ }^{3}$, Jean-Marc Lemaitre ${ }^{2,4}$ \\ and Daniel Fisher ${ }^{1,4, *}$
}

\begin{abstract}
${ }^{1}$ Laboratory of Phosphorylation and Cell Cycle Control, Institut de Génétique Moléculaire de Montpellier, CNRS, UMR5535, Montpellier, France, ${ }^{2}$ Institut de Génomique Fonctionnelle, CNRS, UMR5203, Inserm, U661, Université de Montpellier I et II, Montpellier, France, ${ }^{3}$ Institut de Génétique Humaine, CNRS, UPR1142, Montpellier, France and ${ }^{4}$ Inserm, Equipe Avenir, Montpellier, France
\end{abstract}

In this paper, we describe how, in a model embryonic system, cyclin-dependent kinase (Cdk) activity controls the efficiency of DNA replication by determining the frequency of origin activation. Using independent approaches of protein depletion and selective chemical inhibition of a single Cdk, we find that both Cdk1 and Cdk2 are necessary for efficient DNA replication in Xenopus egg extracts. Eliminating Cdk1, Cdk2 or their associated cyclins changes replication origin spacing, mainly by decreasing frequency of activation of origin clusters. Although there is no absolute requirement for a specific Cdk or cyclin, Cdk2 and cyclin E contribute more to origin cluster efficiency than Cdk1 and cyclin A. Relative Cdk activity required for DNA replication is very low, and even when both Cdk1 and Cdk2 are strongly inhibited, some origins are activated. However, at low levels, Cdk activity is limiting for the pre-replication complex to pre-initiation complex transition, origin activation and replication efficiency. As such, unlike mitosis, initiation of DNA replication responds progressively to changes in Cdk activity at low activity levels.

The EMBO Journal (2008) 27, 758-769. doi:10.1038/

emboj.2008.16; Published online 7 February 2008

Subject Categories: cell cycle

Keywords: CDK; DNA replication; replication origin

\section{Introduction}

In all eukaryotes, cyclin-dependent kinases (Cdks) control both the initiation of DNA replication and the onset of mitosis. Whereas M-phase entry is absolutely dependent on Cdk1-cyclin B complexes (Nurse, 1990), Cdk control of DNA replication appears to vary from system to system, and in metazoans relies more on Cdk2 and E- and A-type cyclins. In fission yeast, we found that a single variation in activity of

\footnotetext{
${ }^{*}$ Corresponding author. Laboratory of Phosphorylation and Cell Cycle Control, CNRS, UMR 5535-Institut de Génétique Moléculaire, 1919 Route de Mende, Montpellier cedex 5 34293, France. Tel.: +33467 6136 94; Fax: + 334670402 31;

E-mail: fisher@igmm.cnrs.fr
}

Received: 3 September 2007; accepted: 18 January 2008; published online: 7 February 2008 one Cdk-cyclin complex is sufficient for both mitosis and S-phase control (Fisher and Nurse, 1996). These and other results led us to propose a quantitative model of cell-cycle regulation in which very low Cdk activity allows replication complex formation, some Cdk activity then activates DNA replication and high activity promotes mitosis and prevents DNA re-replication. In this model, qualitative aspects (phosphorylation of S-phase versus mitotic substrates by different Cdk-cyclin complexes) could result from quantitative (different affinities/kinetics) and spatiotemporal (expression/destruction/localization patterns of cyclins) properties, rather than absolute specificities between kinase and substrate.

With regard to the initiation of DNA replication, various aspects of the quantitative model have been supported by elegant experiments in Xenopus, yeast and mice models. In Xenopus egg extracts, mitotic cyclin B, if nuclear localized, could promote DNA replication in the absence of the S-phase cyclin E (Moore et al, 2003). In budding yeast, the mitotic Clb1-4 cyclins can substitute for the S-phase Clb5-6 cyclins (Donaldson et al, 1998), and can interact with both S-phase and M-phase substrates (Loog and Morgan, 2005). In mice, Cdk2 and its associated E-type cyclins are non-essential for DNA replication in most cells (Berthet et al, 2003; Geng et al, 2003; Ortega et al, 2003; Parisi et al, 2003). Cdk2 is also not required for proliferation of many cancer cell lines (Tetsu and McCormick, 2003). In fact, Cdk1 is sufficient in the absence of Cdk2, 4 and 6 to promote the cell cycle in mouse fibroblasts (Santamaria et al, 2007), and is required for DNA replication in the absence of Cdk2 (Aleem et al, 2005; Hochegger et al, 2007). So the question is now not so much whether Cdk1 complexes in metazoans can promote DNA replication when other complexes are absent, as: do they in normal circumstances? Whether or not Cdk1 might normally be an important kinase for initiating DNA replication in mammalian cells is hard to assess, as its inhibition primarily blocks mitosis.

Why, also, are there multiple Cdk-cyclin complexes present with S-phase promoting ability? In Xenopus egg extracts, but not in mammalian cells, Cdk2 and cyclin E are both required for DNA replication (Fang and Newport, 1991; Jackson et al, 1995). Similar findings are true for early Drosophila embryos (Knoblich et al, 1994; Jacobs et al, 2001). These results are surprising because Cdk1 and cyclin A are present, and in Xenopus extracts, exogenous Cdk1 and cyclin A can promote DNA replication in the absence of Cdk2 (Chevalier et al, 1995; Strausfeld et al, 1996). Nevertheless, in mammalian cell extracts, cyclin A and cyclin E appear to have distinct S-phase-promoting functions (Coverley et al, 2002). Possibly, rapid embryonic cell cycles have an organization of DNA replication different from that of somatic cells. Xenopus egg extracts recapitulate the embryonic system, in which origins of replication are spaced about every $10 \mathrm{~kb}$ (Herrick et al, 2000; Lucas et al, 2000; Blow et al, 2001), compared with every $50-300 \mathrm{~kb}$ in somatic cells. As Cdk activity 
is required to activate origins of replication (Jares and Blow, 2000; Hashimoto and Takisawa, 2003), this might impose strict requirements for $\mathrm{Cdk} 2$-cyclin $\mathrm{E}$ activity for efficient activation of replication origins. Cdk2-cyclin E might thus be rate-limiting for an embryonic system but not for somatic DNA replication in which origin activation is not rate limiting. This may well be reflected in Cdk-cyclin complexes present at different stages of the cell cycle between the two systems. In mammalian cells, Cdk1 and Cdk2 both bind cyclin A and cyclin E (Aleem et al, 2005), with cyclin A being the major Cdk2 partner at S-phase. However, in Xenopus egg extracts, cyclin A only associates with $\mathrm{Cdk} 1$, whereas Cdk2 is complexed exclusively with cyclin E (Strausfeld et al, 1996).

The quantitative model implies that Cdk activity required for entry into S-phase should be much lower than that required for mitotic onset, and there is some evidence for this in Xenopus (Chevalier et al, 1995; Strausfeld et al, 1996), although this activity has not been well quantified. At mitotic onset, a switch-like response ensures that different events of M-phase are only triggered at high Cdk activity, and no such events are seen below this threshold (Pomerening et al, 2003). Whether or not there is an analogous Cdk threshold for replication origin firing is not known.

Almost all the data on which the quantitative model is based come from knockout or knockdown approaches. Yet this may introduce an important bias, as in the latter case, other Cdks/cyclins or their potential S-phase-promoting functions might compensate or even be upregulated. Chemical inhibition might not allow the same compensation. Thus, comparison of knockout approaches with specific chemical inhibition in the same system should yield important insights.

In this study, we analyse the molecular basis for the apparently specific requirements for individual Cdks and cyclins for the initiation of DNA replication in Xenopus egg extracts, and present how qualitative and quantitative manipulation of Cdk activity affects replication origin activation. We also asked whether chemical inhibition phenocopies the absence of Cdk-cyclin complexes.

\section{Results}

\section{Cdk1 and Cdk2 both accumulate on chromatin early during DNA replication}

Cyclin E associates with chromatin during DNA replication in both Xenopus extracts and mammalian cells (Furstenthal et al, 2001; Geng et al, 2007). Activation of the pre-replication complex (pre-RC) allows assembly of the pre-initiation complex (pre-IC), containing Cdc45, proliferating-cell nuclear antigen (PCNA), the Go, Ichi, Nii, San complex (GINS) and the MCMs, and requires Cdk activity in both yeast (Zou and Stillman, 1998) and Xenopus (Jares and Blow, 2000; Hashimoto and Takisawa, 2003). We therefore asked whether the essential functions of Cdks to initiate DNA replication might occur directly on chromatin. To answer this question, we analysed proteins associated with chromatin purified from interphase Xenopus egg extracts (IEE) at different time points during DNA replication. We found that not only cyclin E, but also Cdk2, and, surprisingly, Cdk1 (see also Figure 2; Supplementary Figure S1), accumulate on chromatin in early S-phase, with a maximum slightly preceding that of Cdc45
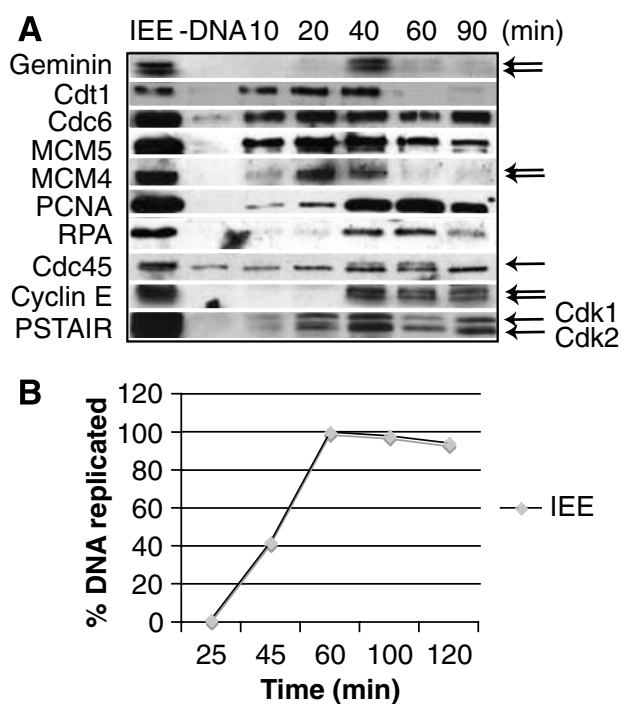

Figure $1 \mathrm{Cdk} 1$ and $\mathrm{Cdk} 2$ both accumulate on chromatin during DNA replication. (A) Chromatin was purified from replicating nuclei at the indicated time points and blotted with antibodies against proteins of the pre-RC (Cdt1, geminin, Cdc6, mini chromosome maintenance (MCMs)), the pre-IC (Cdc45, arrow; lower band is contaminant; RPA, PCNA) and Cdk1/2 (PSTAIR, which recognizes both Cdk1, upper band, and Cdk2, lower band, arrows) or Xcyclin E. MCM4, geminin and cyclin E are all present in two isoforms. (B) Time course of DNA replication in this extract. A full-colour version of this figure is available at The EMBO Journal Online.

and PCNA accumulation (Figure 1). This result suggests that Cdks might be recruited to origins to regulate the pre-RC to pre-IC transition, and that both Cdk1 and Cdk2 might normally be involved in promoting DNA replication.

\section{DNA replicates efficiently with very low Cdk activity, both Cdk1 and Cdk2 are involved and endogenous Cdk1, Cdk2, cyclin A or cyclin E are minimally sufficient}

To study Cdk activities required for DNA replication, as compared with mitosis, we first measured Cdk1 and Cdk2 histone $\mathrm{H} 1$ kinase activity in $\mathrm{M}$-phase and interphase extracts from the same batch of eggs. Cdk1 and Cdk2 were immunoprecipitated from extracts of $\mathrm{M}$-phase or activated eggs (see methods) using specific antibodies. Cdk protein levels are similar, but Cdk1 activity is sixfold lower in interphase than M-phase, whereas Cdk2 activity is 2-3 times higher in interphase than in M-phase (Figure 2A). Cdk1 still significantly contributes to overall histone $\mathrm{H} 1$ activity of Cdks in interphase extracts (Figure 2A and D). We estimated that the concentrations of the two expressed cyclins, cyclin A1 and cyclin E1 (hereby referred to as cyclins A and E), in interphase egg extracts is about 10 and $30 \mathrm{nM}$, respectively (Supplementary Figure S1). Indeed, most cyclin A1 is not degraded upon egg activation, and only afterwards does it associate with a Cdk (Kobayashi et al 1991). We could detect only Cdk1 associated with cyclin A, as reported (Strausfeld et al, 1996), whereas cyclin E mostly bound to Cdk2, but also, in some experiments, apparently to a small amount of Cdk1 (Figure 3A), as in mammalian cells (Aleem et al, 2005). We then specifically (Figure 2B-D; Supplementary Figure S1) depleted Cdk1, Cdk2, or both, to measure the effects on the efficiency of DNA replication. Interestingly, although one 
A

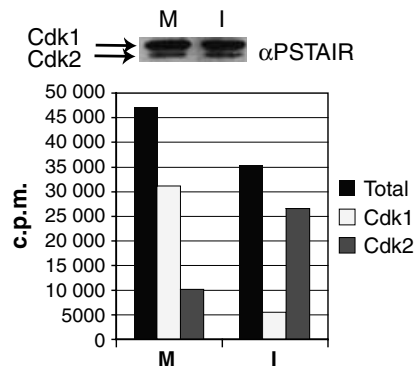

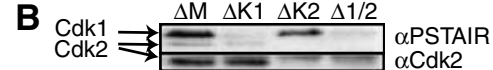

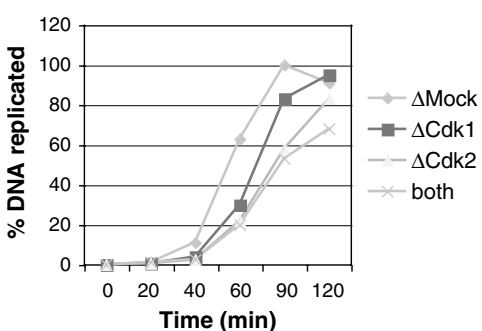

C
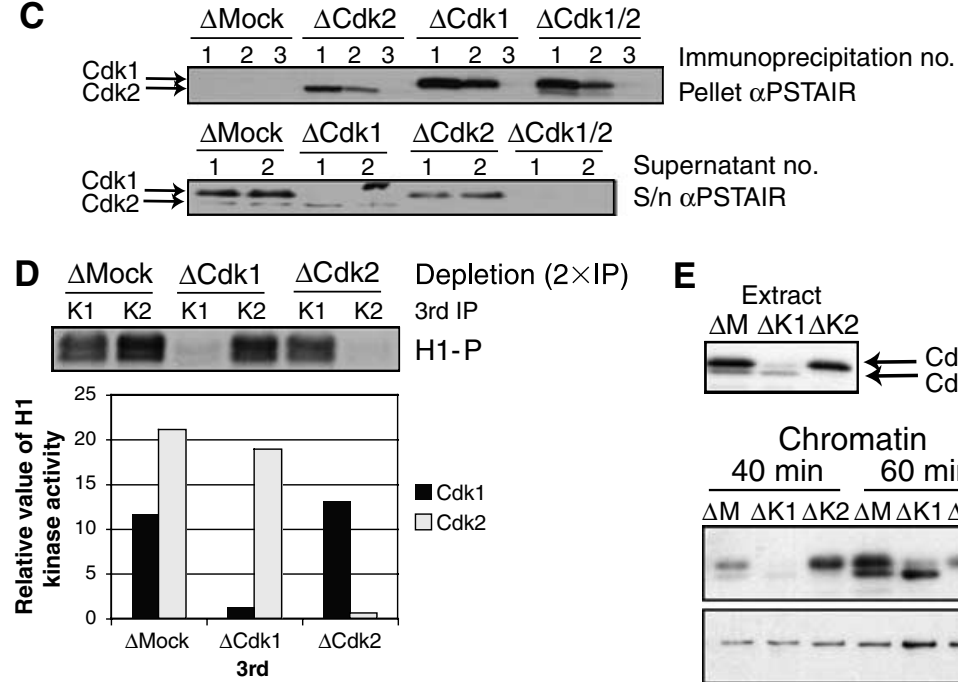

E

Extract

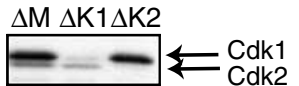

Chromatin

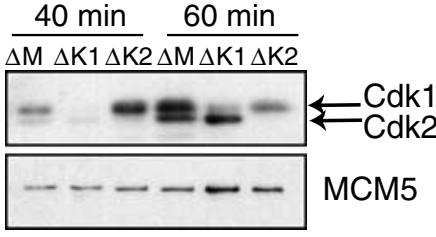

$\mathbf{F}$

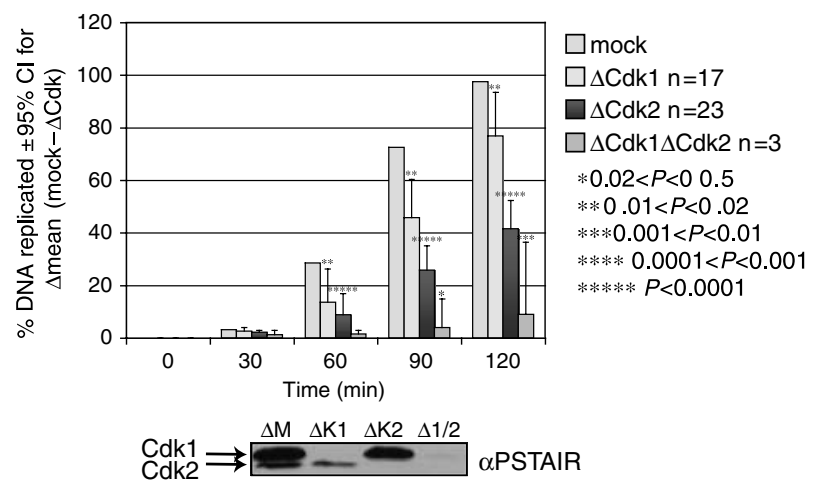

Figure 2 Cdk1 and Cdk2 are both important for embryonic DNA replication but neither is essential. (A) Quantitative analysis of Cdk-cyclin complexes. Total Cdk or immunoprecipitated Cdk1 and Cdk2 kinase activities were measured from equal egg equivalents of extracts from metaphase arrested eggs (M) and eggs from the same pool released into interphase (I). Western blot (upper panel) shows that Cdk1 and Cdk2 concentrations did not change. (B) Elimination of most of Cdk1, Cdk2 or both delays, but does not prevent, DNA replication. IEEs partially immunodepleted $(\Delta)$ with XCdk1 (K1) or XCdk2 (K2) antibodies, both (1/2) or control antibodies (mock, M) were incubated in a replication assay with sperm nuclei as described under Materials and methods. Percentage of input DNA replicated was analysed at the indicated times. Upper panel: depletion controls by western blot. (C) One round of depletion with Cdk2 or Cdk1 antibodies specifically removes most of the respective Cdk, whereas two rounds remove all. Upper panel: western blots of the IPs from the first or second round of immunodepletion $(1,2)$, or a third IP of the remainder (3), with the indicated antibodies; lower panel: depleted extract supernatants after one or two rounds of depletion $(\Delta)$. (D) Two rounds of immunodepletion with the indicated antibodies $(\Delta \mathrm{Cdk} 1,2)$ from $100 \mu$ IEEs were followed by a third IP with XCdk1 (K1) and XCdk2 (K2) antibodies from $10 \mu \mathrm{l}$ of the depleted extract. This was then used in a Cdk H1 histone kinase assay. Phosphorylated H1 (H1-P) was quantified by phosphorimager (graph). (E) Mock, or depletion of Cdk1 ( $\Delta \mathrm{K} 1)$ or $\mathrm{Cdk} 2(\Delta \mathrm{K} 2)$ from extracts (upper panel) is reflected by a depletion of the respective protein from the chromatin (lower panels). MCM5 is shown as a chromatin loading control. (F) Replication time courses were performed from IEEs immunodepleted $(\Delta)$ with XCdk1 or XCdk2 antibodies, or both simultaneously, in 17,23 or 3 independent experiments, respectively. Mean \% of DNA replicated at each time point; error bars for Cdk-depleted samples: $95 \%$ confidence interval for reduction in mean \% DNA replicated compared with mock depletion for each experiment. Statistical significance of differences (paired $t$-test of mock versus depleted samples) is indicated by asterisks. A full-colour version of this figure is available at The EMBO Journal Online.

round of immunoprecipitation could deplete around $80 \%$ of the respective protein from the extract, this only causes a slight delay in DNA replication (Figure 2B), suggesting that efficient initiation of DNA replication in egg extracts is robust to large changes in Cdk activity. However, two rounds of depletion quantitatively depleted the target proteins 
A

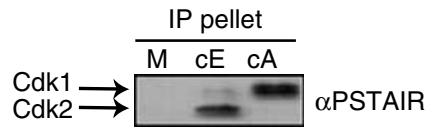

B
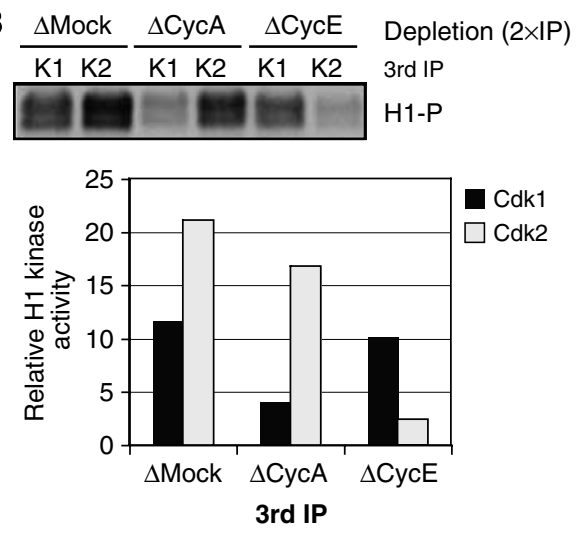

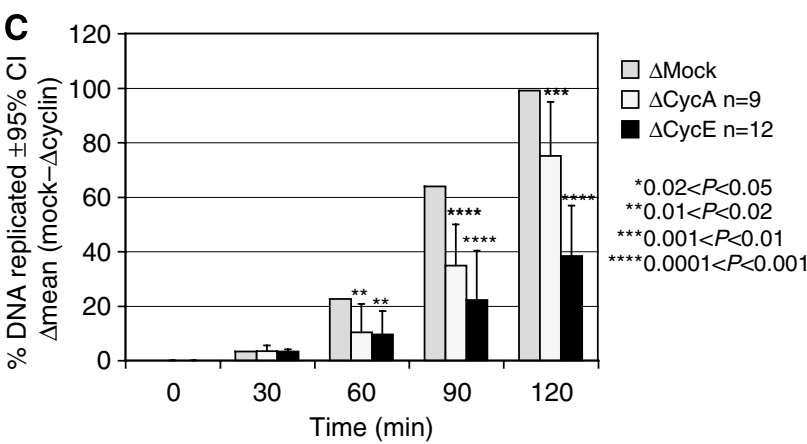

D

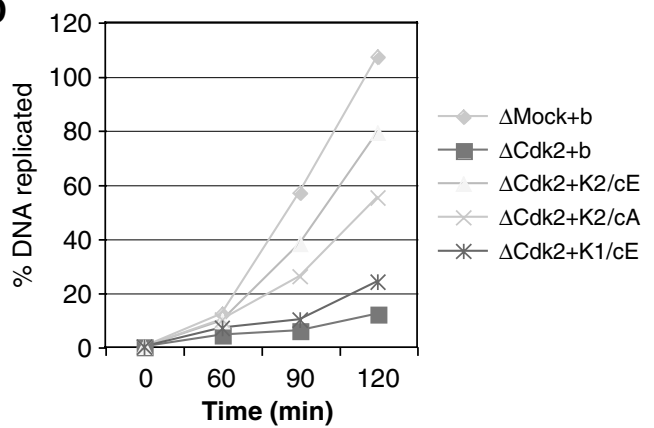

Figure 3 Cyclin involvement in Cdk activity and requirements for DNA replication. (A) Mock (M) or cyclin E and A (cE, cA) immunoprecipitates from $10 \mu \mathrm{l}$ IEE were blotted with PSTAIR antibody. (B) As in Figure 2D; depletions $(\Delta \mathrm{CycA}$, E) were followed by a third IP with XCdk1 (K1) and XCdk2 (K2) antibodies, which were then used in an H1 kinase assay. (C) As in Figure 2F, but depletions using cyclin A or cyclin $\mathrm{E}$ antibodies, from 9 or 12 independent experiments, respectively. Error bars: $95 \%$ CI for difference in mean \% DNA replicated compared with mock; asterisks: statistical significance (paired $t$-test). (D) Mock-depleted or Cdk2-depleted IEE, complemented with buffer alone (B) or recombinant active human Cdk2-cyclin E (K2/cE, $120 \mathrm{nM}$ final concentration), Cdk2-cyclin A (K2/cA, 120 nM) or Cdk1-cyclin $\mathrm{E}(\mathrm{k} 1 / \mathrm{cE}, 30 \mathrm{nM})$, were used in replication time-course assays. A full-colour version of this figure is available at The EMBO Journal Online.

(Figure 2C) and their associated histone H1 kinase activities (Figure 2D). We verified also that Cdk1 and Cdk2 depletion prevented their accumulation on chromatin (Figure 2E). Using these conditions, mock depletion with a nonspecific antibody had no effect and allowed $100 \%$ of input DNA to be replicated within $2 \mathrm{~h}$ (Figure $2 \mathrm{~F}$ ). Cdk2 depletion, as expected, caused a very significant inhibition of replication, although replication was not entirely prevented. To be certain we repeated this experiment over 20 times. In none of the repetitions was replication abolished, and there was some variability between the experiments, but on average over $40 \%$ of input DNA was replicated by $2 \mathrm{~h}$ (Figure $2 \mathrm{~F}$ ), even though we could not detect Cdk2 after depletion. Cdk1 depletion caused a small delay in replication (Figure 2F). Again, this experiment was repeated many times to be sure that this was not just experimental variation.

As efficient DNA replication appears to require high nuclear concentrations of Cdk2-cyclin E (Moore et al, 2002), and Cdk2 depletion also removed most cyclin E (Supplementary Figure S1), we performed similar experiments to examine the effects of depleting cyclins E or A. Depleting cyclin A depleted most Cdk1 kinase activity, whereas depletion of cyclin E only slightly reduced Cdk1 kinase activity, but significantly depleted Cdk2 activity (Figure 3B). With cyclin E depletion, we obtained similar results as with Cdk2 depletion (Figure 3C). Cyclin A depletion, similarly to Cdk1 depletion, only slightly reduced DNA replication (Figure $3 \mathrm{C}$ ).

Although double depletions to simultaneously deplete both kinases proved technically difficult, in experiments where both Cdk1 and Cdk2 were effectively removed, less than $10 \%$ of input DNA was replicated (Figure 2F), suggest- ing that in the absence of $\mathrm{Cdk} 2$, Cdk 1 is required, and vice versa, and both are necessary to replicate DNA with high efficiency. We suspect that the remaining $10 \%$ is accounted for by residual Cdk1 (on close inspection, a minor band is detectable; Figure 2F) that we are unable to deplete without compromising the integrity of the extract. A similar result was obtained by combining cyclin A and cyclin E depletion (Supplementary Figure S2).

We also repeated depletions from an egg extract prepared in the presence of $100 \mu \mathrm{g} / \mathrm{ml}$ cycloheximide, to prevent de novo synthesis of cyclins before commencing the replication assay (in which cycloheximide is always added). Cdk1 depletion still delayed replication, and DNA could still replicate to $15 \%$ after Cdk2 depletion (Supplementary Figure S3; similar to Figures 3D, 6A and Supplementary Figure S5C). There was also little effect of cycloheximide on Cdk1 and Cdk2 activity in a 2-h time course (Supplementary Figure S3). These results suggest that involvement of Cdk1 and Cdk2 in DNA replication does not require new cyclin synthesis, although in vivo, cyclin synthesis will certainly occur on entry into interphase.

Next, we asked which recombinant Cdk-cyclin complexes could restore efficient replication in Cdk2-depleted extracts. Previously, it was found that Cdk2-cyclin A could restore replication to a suc1-depleted extract (which removes both Cdk1 and Cdk2 complexes), whereas Cdk2-cyclin E was less efficient (Jackson et al, 1995; Strausfeld et al, 1996; Moore et al, 2002). We first verified that adding an excess of $\mathrm{H} 1$ kinase activity of recombinant human Cdk2-cyclin A, Cdk1cyclin E or Cdk2-cyclin E to control extracts did not affect DNA replication (not shown). Adding Cdk2-cyclin A or Cdk2-cyclin E complexes at $120 \mathrm{nM}$ (Supplementary Figure 
S4) to Cdk2-depleted extracts could restore DNA replication at $2 \mathrm{~h}$ from 12 to 50 or $80 \%$, respectively (Figure 3D). The added $\mathrm{H} 1$ kinase activity correlated well with Cdk2 H1 kinase activity in the extract (Supplementary Figure S4). Cyclin E alone did not rescue DNA replication (Supplementary Figure S5), and preincubating Cdk2-cyclin E with the Cdk inhibitor, Nu6102, which is specific for Cdk2 in the extract (see Figure 4), abolished the rescue (Supplementary Figure S5). Thus, unlike mammalian cells exiting quiescence (Geng et al, 2007), Cdk2 kinase activity, and not simply cyclin E presence, is required for DNA replication in Xenopus egg extracts. A 30-nM concentration of Cdk1-cyclin E could also partly restore replication activity (to $24 \%$ ) to a Cdk2-depleted extract (Figure 3D); the poorer rescue by this complex might simply be due to its lower activity (Supplementary Figure S4), although a lower or higher concentration of recombinant complexes, or a combination of cyclin $\mathrm{E}$ and cyclin A or Cdk1 and Cdk2 complexes, did not improve these values (not shown). Recombinant Cdk complexes were somewhat less efficient at rescuing DNA replication when
A

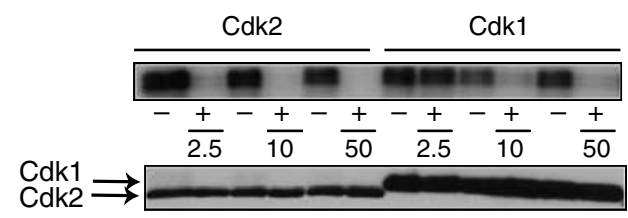

C

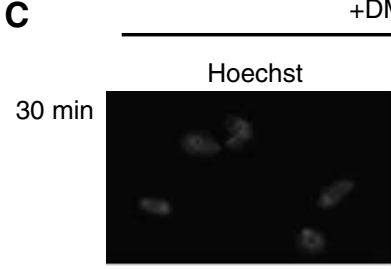

+DMSO

$60 \mathrm{~min}$

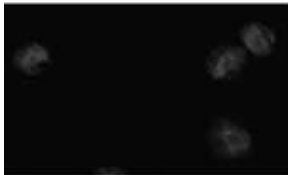

$120 \mathrm{~min}$
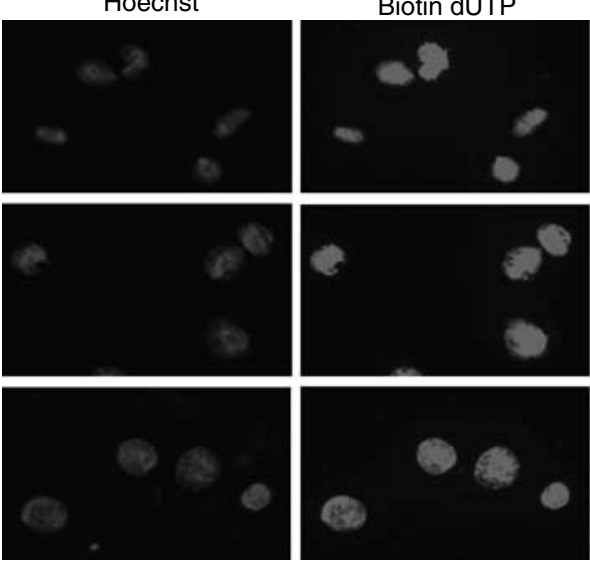

IP pellets

H1-P

Nu6102

$(\mu \mathrm{M})$

WB $\alpha$ PSTAIR

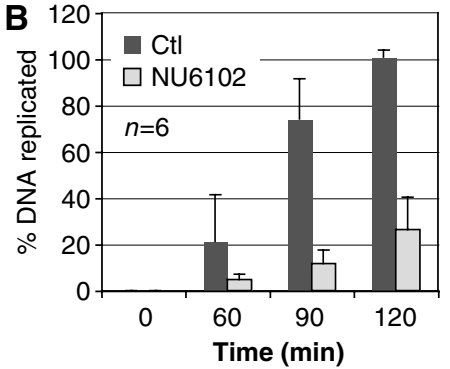

$+\mathrm{NU} 6102$

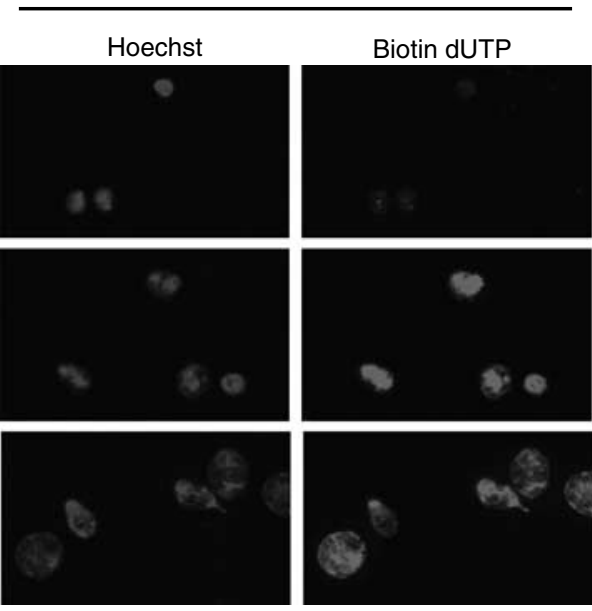

D

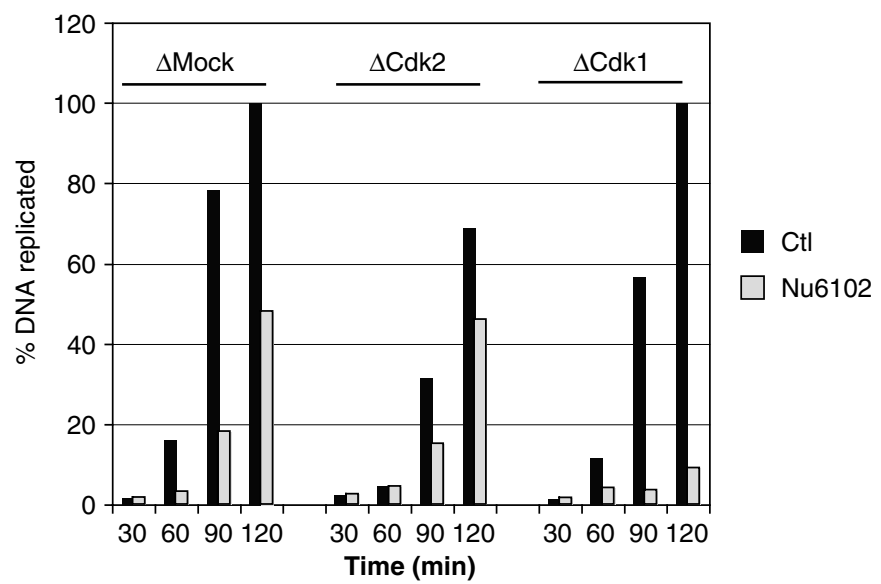

Figure 4 Specific chemical inhibition of Cdk2 shows that Cdk1 is essential for DNA replication in the absence of Cdk2. (A) Cdk1 or Cdk2 immunoprecipitated from $10 \mu \mathrm{l}$ IEE was used in ${ }^{33} \mathrm{P}-\mathrm{H} 1$ kinase assays at the different indicated concentrations of Nu6102 (50 $\mu \mathrm{M}$ total ATP). Lower panel: PSTAIR western blots of the kinase assays for IP and loading control. (B) Replication time courses were performed from control (mock) or $100 \mu \mathrm{M}$ Nu6102 treated IEE; mean \pm s.d. \% of DNA replicated at each time point in six independent experiments. (C) As in panel B, but replication was assessed by immunofluorescence of incorporated biotin-dUTP at the indicated time points. (D) As in panel B, but control or Nu6102 treatment of IEE depleted with nonspecific antibodies (mock) or XCdk1 or XCdk2 antibodies. A full-colour version of this figure is available at The EMBO Journal Online. 
cyclin E was depleted (Supplementary Figure S6). Thus, the effect of depleting a particular Cdk on DNA replication in Xenopus extracts appears to be due to an overall reduction of Cdk activity, which can be complemented by heterologous Cdk complexes. However, maximum efficiency of DNA replication might perhaps only be achieved with all endogenous Cdk complexes.

\section{Specific chemical inhibition of Cdk2 shows that Cdk1 is involved in DNA replication in the presence of Cdk2, and defines the kinase activity required for efficient DNA replication}

The above results strongly suggest that both Cdk1 and Cdk2 complexes are normally involved in promoting DNA replication, but as they result from depletion approaches, we sought independent confirmation by chemical inhibition. Nu6102 is a potent specific ATP-competitive Cdk inhibitor (Davies et al, 2002). We verified that Nu6102 inhibited the complexes of recombinant Xenopus Cdk2 with both cyclins $\mathrm{E}$ and A (Supplementary Figure S7) in the conditions of the extract. Nu6102 was also an efficient inhibitor of Cdk2 immunoprecipitated from extracts (Figure 4A, left lanes). However, it was much less effective against immunoprecipitated Cdk1 (Figure 4A, right lanes), and inhibited Cdk2 but not Cdk1 at an Nu6102/ATP ratio of 1:20 (i.e., $2.5 \mu \mathrm{M}$ Nu6102 with $50 \mu \mathrm{M}$ ATP). We found a similar differential sensitivity with human Cdk1 and Cdk2 complexes (Supplementary Figure S8). Therefore, in the conditions of the extract ( $2 \mathrm{mM}$ ATP), $100 \mu \mathrm{M}$ Nu6102 should completely inhibit Cdk2 but not Cdk1.

Accordingly, we found that $100 \mu \mathrm{M}$ Nu6102 inhibited DNA replication in egg extracts by $60-90 \%$ (Figure 4B). Nu6102 did not decrease the frequency of nuclei that replicate, but caused homogenously weakened incorporation of biotin-dUTP into DNA of replicating nuclei (Figure 4C). This confirms that the kinase activity of Cdk2 is required for efficient DNA replication. Similarly to $\mathrm{Cdk} 2$ depletion, Nu6102 inhibition never entirely blocked DNA replicationon average $30 \%$ of DNA was replicated at $2 \mathrm{~h}$. We found similar results with alsterpaullone, another potent Cdk2 inhibitor (Knockaert et al, 2002; Supplementary Figure S9).

To test whether the remaining DNA replication in extracts after Nu6102 inhibition was still due to residual activity of Cdk2, or to Cdk1, or another kinase, we combined Cdk2 or Cdk1 depletion with Nu6102 treatment. Cdk2 depletion was not synergistic with Nu6102 inhibition (Figure 4D). However, when Cdk1 depletion was combined with Nu6102, replication was almost completely abolished (Figure 4D). Therefore, the $30 \%$ (on average) DNA replication efficiency after inhibition by Nu6102 is not due to residual Cdk2 activity, but to Cdk1. This confirms that Cdk1 promotes DNA replication even when Cdk2 is still present (albeit inhibited), and that Cdk1 involvement is not an artefact of having removed Cdk2. It also confirms that most of the remaining $40 \%$ (on average) DNA replication efficiency after Cdk2 depletion is due to Cdk1 and not to residual Cdk2. When $80 \%$ of both Cdk1 and Cdk2 were removed by depletion (see Figure 2B), in the presence of Nu6102, there is less than $7 \%$ of initial $\mathrm{Cdk} 1 / 2$ histone $\mathrm{H} 1$ kinase activity in the interphase extract (around $1 \%$ of M-phase $\mathrm{H} 1$ kinase activity; see Figure $2 \mathrm{~A}$ ), but DNA still replicated at $30 \%$ efficiency (not shown). Thus, in Xenopus egg extracts, the vast majority of Cdk activity is dispensable for DNA replication. These results confirm that both Cdk1 and Cdk2 are involved in DNA replication, and demonstrate selective chemical inhibition of $\mathrm{Cdk} 2$ without inhibiting Cdk1 function.

\section{Reducing Cdk activity quantitatively reduces the pre-RC-to-pre-IC transition}

Cdk activity is essential for DNA replication in yeast only for converting pre-RCs to pre-ICs at the origins (Zou and Stillman, 1998). Cdk activity is required in Xenopus egg extracts for pre-IC formation (Jares and Blow, 2000; Hashimoto and Takisawa, 2003). Confirming these results, we observed that Cdk2 inhibition by Nu6102 did not inhibit pre-RC formation (Cdc6 and the MCM complex were loaded), but reduced Cdc45 and PCNA loading roughly proportionally to the decrease in DNA replication (Figure 5A). A time course of Nu6102 addition showed that Cdk2 inhibition affected DNA replication only before, but not after, Cdc45/PCNA accumulation (Figure 5B). Depletion of cyclin E similarly inhibited this transition (Figure 5C). Thus, in Xenopus extracts, as in yeast, Cdk-cyclin complex activity strictly regulates the pre-RC-to-pre-IC transition.

\section{Origin activation as a buffer for Cdk activity}

Egg extracts simulate early Xenopus development in which S-phase and M-phase are extremely rapid, and DNA replication occurs without specific origins (Hyrien et al, 1995) and much smaller replicons than in somatic cells (Herrick et al, 2000; Lucas et al, 2000; Blow et al, 2001). Yet DNA replication can occur with only very low Cdk activity. It may be that large changes in Cdk activity are 'buffered' by replicating with fewer origins, but larger replicons.

To address this question, we performed molecular combing of single DNA molecules to visualize individual origin activation. We used a low concentration $(5 \mu \mathrm{M})$ of aphidicolin to slow down replication forks (Supplementary Figure S10). This allows short tracks of bromodeoxyuridine (BrdU) incorporation (we did not count isolated dots), which correspond to activated replication origins, but minimizing interference from the S-phase checkpoint. In Xenopus extracts, $250 \mu \mathrm{M}$ aphidicolin activates a caffeine-sensitive checkpoint, inhibiting origin usage (Marheineke and Hyrien, 2001, 2004; Shechter et al, 2004), and at high DNA concentrations (10-20 ng DNA/ $\mu \mathrm{l}), 5 \mu \mathrm{M}$ aphidicolin may also slightly activate the checkpoint (Luciani et al 2004). We therefore used only 4 ng DNA/ $\mu$ l.

Extracts were depleted for cyclin A, cyclin E, Cdk1 and Cdk2, and/or Cdk2 activity was inhibited by Nu6102. Compared with control extracts, DNA replication efficiency was reduced, as expected, by $35-90 \%$, depending on the protein targeted (Figure 6A). DNA was allowed to incorporate BrdU for 75 min before treatment for combing. Inter-origin distances were measured from centre-centre of adjacent BrdU tracks on combed DNA (Figure 6B). Each of the Cdk or cyclin manipulations caused an increase in mean interorigin spacing and standard deviation of the mean (range of replicon sizes) (Table I; Figure 6C; Supplementary Figure S11), and increased the combined length of unlabelled fibres (Table I). Nu6102, Cdk2, Cdk1 and cyclin E depletions all increased mean inter-origin spacing by $50-125 \%$. Even though Cdk1 and cyclin A depletions had a smaller effect on overall efficiency of DNA replication than Cdk2 deple- 

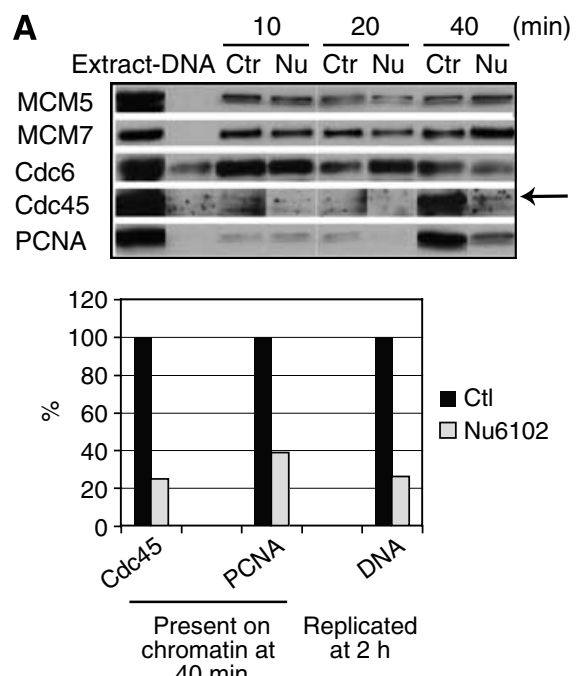
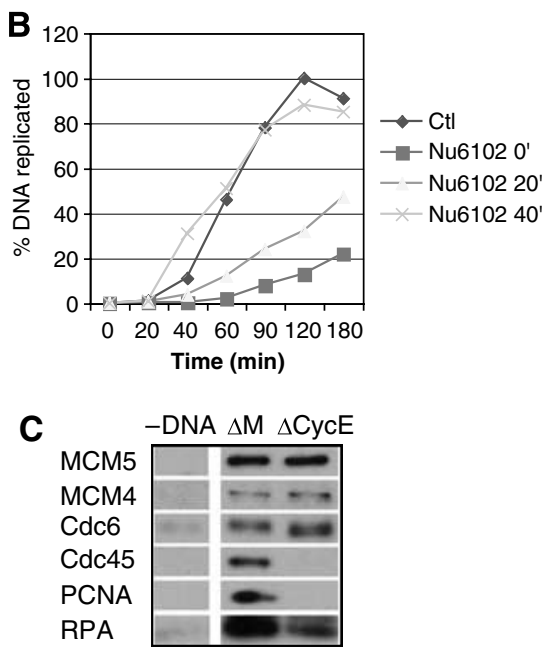

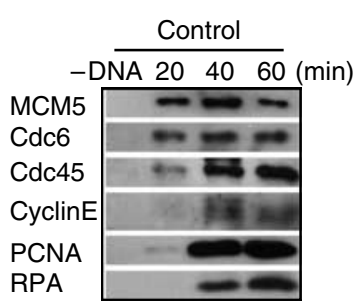

Figure 5 Cdk inhibition quantitatively reduces the pre-RC-to-pre-IC transition, but has no effect on replication efficiency once this transition has occurred. (A) Inhibition of Cdk2 with Nu6102 (Nu) prevents the accumulation of Cdc45 and PCNA on chromatin compared with control (Ctr) extracts. Chromatin-bound Cdc45 and PCNA at 40 min were quantified by densitometry and expressed as \% of control values; the \% of input DNA replicated by $2 \mathrm{~h}$ is shown on the same graph. The image is assembled electronically for clearer presentation, but all lanes were from the same exposure of a western blot of one gel. (B) Replication time courses (left) from control extracts or extracts in which Nu6102 was added at time 0,20 or $40 \mathrm{~min}$; time course of chromatin-bound proteins from control extract in this experiment (western blots, right). (C) Chromatinbound proteins as in panel A, but mock $(\mathrm{M})$ or cyclin $\mathrm{E}(\mathrm{CycE})$ depletions $(\Delta)$. A full-colour version of this figure is available at The EMBO Journal Online.

tions, they still caused a significant increase in mean origin spacing. Thus, efficient replication can occur with fewer origins, allowing a buffer of the effect of Cdk activity on DNA replication. Even with strongly reduced Cdk activity $(\Delta \mathrm{Cdk} 1 / \mathrm{Cdk} 2 i)$, some replication origins could still be activated (Table I; Figure 6C; Supplementary Figure S11). As such, at these low levels Cdk activity is limiting for efficiency of origin firing, but not to the extent that all origin activation is abolished. As there was a combined effect on mean origin spacing of eliminating the activity of both Cdk1 and Cdk2, we conclude that low activities of either kinase can support some origin activation, that $\mathrm{Cdk} 1$ and $\mathrm{Cdk} 2$ cooperatively regulate origin activation, and that, unlike onset of mitosis, in which there is a switch-like 'all or nothing' response to high Cdk activity, initiation of DNA replication shows a progressive response to changes in Cdk activity at low levels.

In Xenopus, origins of replication seem to be organized into clusters of origins $5-15 \mathrm{~kb}$ apart (Blow et al, 2001; Marheineke and Hyrien, 2001, 2004). In our experiments, there were 26.6 initiation events per Mb of DNA in mockdepleted extracts, compared with, for example, 2.2 per $\mathrm{Mb}$ in cyclin E depletions (Table I). This would predict mean interorigin spacings of 38 and $455 \mathrm{~kb}$, respectively, yet the mean inter-origin spacing measured between adjacent tracks was actually 22 and $50.5 \mathrm{~kb}$ (Table I). This clearly reflects clustering of origins, which is also reflected in the distribution of initiation events in shorter fibres (Supplementary Figure S12). To better appreciate and quantify the effects of Cdk manipulation on origin clusters, we used an approximation in which we assigned an origin as belonging to a cluster if its nearest neighbour was separated by less than the sum of the mean plus standard deviation of inter-origin distances for the mock depletion (Figure 6B). Compared with previous estimates of 4-7 origins/cluster (Blow et al, 2001), this gives a conservative estimate of the number of origins per cluster: a mean of 3.4 per cluster for mock depletion, and between 1.7 $(\Delta$ cyclin $\mathrm{E})$ and $2.5(\Delta \mathrm{Cdk} 1 / \mathrm{Cdk} 2 \mathrm{i})$ on reduction of $\mathrm{Cdk}$ activity; thus, slightly fewer origins per cluster (Table I). However, the number of clusters/Mb was greatly decreased, from about 8 (mock) to 5 ( $\Delta \mathrm{Cdk} 1), 2(\Delta \mathrm{Cdk} 2, \Delta \mathrm{Cdk} 1 / \mathrm{Cdk} 2 \mathrm{i})$ or 1.3 ( $\Delta$ cyclin E) (Table I). Thus, relatively efficient overall replication is achieved with fewer origins in Cdk1 or cyclin A depletions because there are more clusters activated than with Cdk2 or cyclin E depletion.

The fact that origin activation was strongly affected when Cdk activity was manipulated suggests that any interference by an aphidicolin-stimulated checkpoint was negligible. However, we confirmed these results in combing experiments without aphidicolin, to allow replication elongation. Although initiation frequencies cannot be determined, due to continued elongation, the BrdU-labelling profile appeared similar to that used to determine origin spacing with aphidicolin (Figure 6D). DNA replication efficiency, as measured by standard ${ }^{33}$ P-labelled dCTP incorporation, corresponded well to that determined in the same experiment by measuring lengths of DNA with incorporated BrdU on combed DNA molecules (Table II). Again, Cdk1 or Cdk2 depletion significantly reduced the fraction of fibres showing BrdU incorporation, and, by inference, the frequency of replication origins activated (Table II), with Cdk2 depletion having a stronger effect than Cdk1 depletion. These results confirm that the main effect of depleting Cdks is a reduction in number of origin clusters activated. On depleting Cdk1 or Cdk2 the mean inter-track + gap distance was also increased (Table II), and the lengths of tracks was decreased, from an average of $16 \mathrm{~kb}$ in controls to $11 \mathrm{~kb}$ in both depletions. As Cdk depletion is reported to not affect replication elongation (Blow and Nurse, 1990), this decrease is probably due to delayed activation of origins. To estimate clustering in this situation, we used Pearson correlation coefficients for lengths 
A

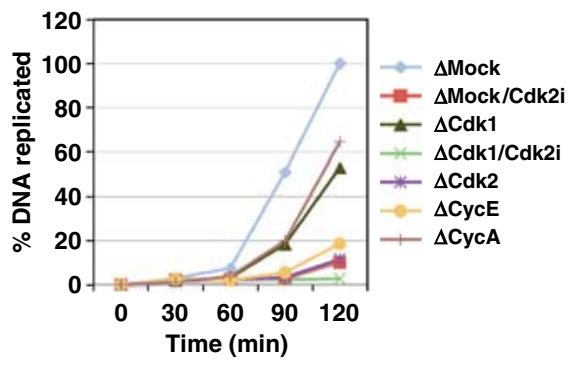

B

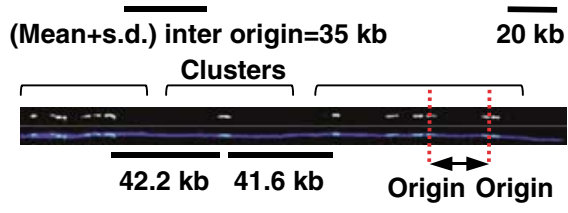

C

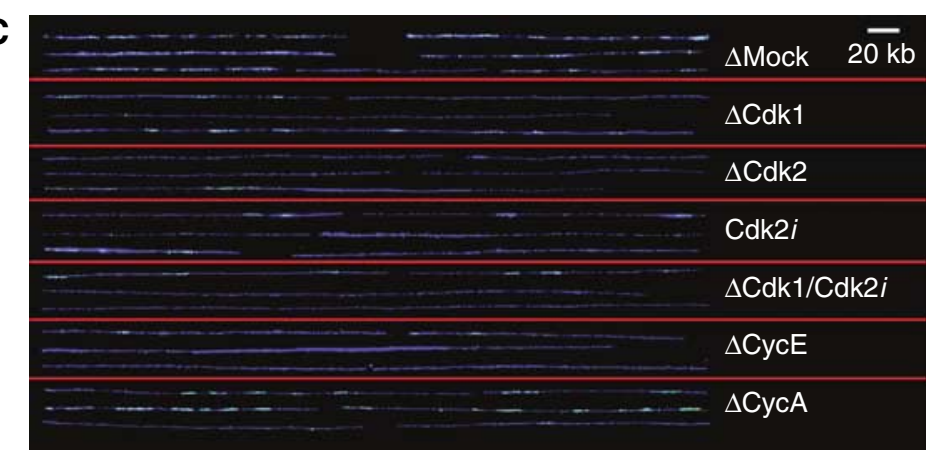

D

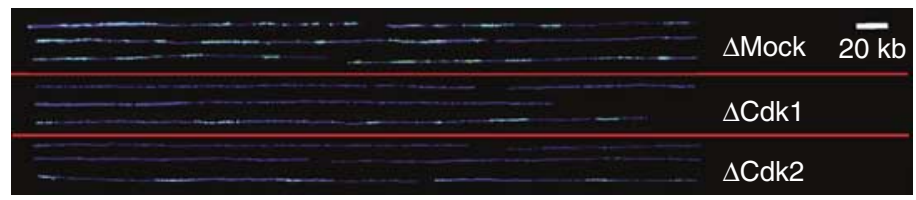

Figure 6 Effects of Cdk1 and Cdk2 on replication origin activation. (A) Replication time course in IEE mock-depleted or depleted $(\Delta)$ of Cdk1, Cdk2, cyclin A or cyclin E, or treated by Nu6102 (Cdk2i) with or without Cdk1 depletion. (B) Diagram showing how replication origins and origin clusters on single combed DNA molecules were classified, as explained in the text. BrdU incorporation is in white (upper), or on the composite image showing the DNA strand (lower) BrdU is in green and DNA in blue. Isolated dots are just background and were not considered. (C) Examples of three combed DNA molecules in each condition, in the presence of $5 \mu \mathrm{M}$ aphidicolin, or (D) without aphidicolin.

of adjacent tracks (Blow et al, 2001; Marheineke and Hyrien, 2004). This statistic was increased from 0.125 ( $\Delta$ mock, $n=49)$ to $0.207(\Delta \mathrm{Cdk} 1, n=39)$ and $0.301(\Delta \mathrm{Cdk} 2, n=31)$ respectively, thus, origin clustering is more evident on depleting Cdks. This probably reflects increased separation of origin clusters and thus reduced track mergers.

\section{Titration of limiting Cdk2 activity by DNA concentration}

We can increase the number of replication origins required to maintain DNA replication efficiency by increasing the concentration of nuclei in the extract. Indeed, untreated extracts replicated 2800 nuclei/ $\mu \mathrm{l}$ with the same efficiency as the standard condition of 1400 nuclei/ $\mu$ l (Figure $7 \mathrm{~A}$ ), that is, absolute dCTP incorporation rate was doubled by doubling the nuclei concentration. Quadrupling the nuclei concentration, however, to 5600 nuclei/ $\mu$ l caused about a $50 \%$ drop in efficiency, due mainly to a decrease in efficiency of origin cluster activation (from control values of 10.3, in this experiment, to about 7.6 clusters/Mb, with a similar number of origins per cluster of 3.25; data not shown), as expected (Marheineke and Hyrien, 2004). When Cdk2 activity was eliminated using Nu6102 at 1400 nuclei/ $\mu$ l, replication was $40 \%$ by $4.5 \mathrm{~h}$, as expected (Figure $7 \mathrm{~B}$ ). This activity should now be rate limiting for replication origin activation. Indeed, we found that at 2800 nuclei/ $\mu$ l, with Nu6102 there was no longer an increase in absolute dCTP incorporation rate, and the efficiency was halved, to $20 \%$ (Figure 7B). At $5600 \mathrm{nu}-$ clei/ $\mu \mathrm{l}$, Nu6102 abolished replication completely (Figure 7B), and no origin activation could be seen by combing (not shown). These results suggest that, at limiting Cdk levels, activation of replication origin clusters is also limiting for replication efficiency.

\section{Discussion}

The relative contribution of $\mathrm{Cdk} 1$ to DNA replication in normal conditions has been difficult to assess due to its essential role in mitosis. In this study, we find that both $\mathrm{Cdk} 1$ and $\mathrm{Cdk} 2$ are involved in the control of DNA replication and replication origin firing, that there is a substantial endogenous Cdk and cyclin redundancy for the initiation of embryonic DNA replication, and no single cyclin or Cdk is absolutely required, in Xenopus egg extracts. This may reconcile some previous controversies from embryonic systems. Schnackenberg et al (2007) and Moreau et al (1998) present that DNA replication in sea urchin embryos is independent of Cdk2, implying that it should require Cdk1. Fang and Newport (1991), on the other hand, stated that Cdk2 is essential, whereas $75 \%$ reduction in Cdk1 by immunodepletion had no effect on DNA replication in Xenopus egg extracts. As Cdk1 is an abundant protein, it is difficult to eliminate by depletion (or by RNAi in other systems), to study its normal role in the presence of Cdk2. Here, we show by two independent approaches, that in Xenopus egg extracts Cdk1 makes an important contribution to Cdk control of DNA replication in the presence of $\mathrm{Cdk} 2$, and is essential in the absence of Cdk2. One interesting observation was that although in Cdk2-depleted extracts there was always significant residual DNA replication, in different experiments this varied from 10 to $70 \%$, and variability was also seen in Cdk1 depletions. We propose two explanations, both based on the observation that only extremely low Cdk activity is required for DNA replication. First, it is possible that our depletions varied slightly in efficiency such that variations in residual, yet still undetectable, $\mathrm{Cdk} 1$ or Cdk2 activity have large effects on replication. Both Cdk2 and Cdk1 could conceivably be essential for DNA replication in this system, and whereas we are able to completely deplete and specifically inhibit Cdk2, there is much more Cdk1 in the extract, of which only a trace might be sufficient to allow replication in the presence of Cdk2. Indeed, in some extracts Cdk1 depletion alone was sufficient to strongly inhibit DNA replication. Alternatively, while relative involvement of Cdk1 and Cdk2 in regulating DNA replication is globally similar between extracts, that 
Table I Molecular combing data upon Cdk1, Cdk2 or cyclin depletion or inhibition

\begin{tabular}{|c|c|c|c|c|c|c|c|c|}
\hline & $\begin{array}{l}\% \text { DNA replicated } \\
\text { at } 75 \text { min } \\
\left(\alpha^{-3} \mathrm{P} \text { dCTP inc.) }\right.\end{array}$ & $\begin{array}{l}\% \text { BrdU + }^{\text {fibres }} \\
\end{array}$ & $\begin{array}{l}\text { No. initiation } \\
\text { events/Mb }\end{array}$ & $\begin{array}{l}\text { Expected mean } \\
\text { inter-origin } \\
\text { spacing }(\mathrm{kb})^{\mathrm{b}}\end{array}$ & $\begin{array}{l}\text { Observed mean } \\
\text { inter origin } \\
\text { spacing } \pm \\
\text { s.d. }(\mathrm{kb})^{\mathrm{c}}\end{array}$ & $\begin{array}{l}\text { No. inter- } \\
\text { origins } \\
\text { measured }\end{array}$ & $\begin{array}{l}\text { Mean no. } \\
\text { origins/, } \\
\text { 'cluster'd }\end{array}$ & $\begin{array}{c}\text { No } \\
\text { 'clusters'/ } \\
\text { Mb }^{\mathrm{d}}\end{array}$ \\
\hline Mock & 29.2 & 72.5 & 26.6 & 37.6 & $22.4 \pm 12.9$ & 57 & 3.4 & 7.9 \\
\hline$\Delta \mathrm{Cdk} 1$ & 10.7 & 42.4 & 10.4 & 96.2 & $39.6 \pm 31.1$ & 58 & 2.2 & 4.7 \\
\hline$\Delta \mathrm{Cdk} 2$ & 2.9 & 12.8 & 3.7 & 270.2 & $38.5 \pm 23.9$ & 44 & 2.3 & 1.6 \\
\hline Cdk2i & 2.6 & 16.1 & 5.3 & 188.7 & $34.3 \pm 25.3$ & 66 & 2.1 & 2.5 \\
\hline $\begin{array}{l}\Delta \mathrm{Cdk} 1 / \\
\mathrm{Cdk} 2 \mathrm{i}\end{array}$ & 2.6 & 18.0 & 4.9 & 204.1 & $48.7 \pm 40.8$ & 61 & 2.5 & 2.0 \\
\hline$\Delta$ CусЕ & 3.8 & 15.2 & 2.2 & 454.5 & $50.5 \pm 52.1$ & 43 & 1.7 & 1.3 \\
\hline$\triangle \mathrm{CycA}$ & 11.9 & 65.4 & 17.4 & 57.5 & $25.8 \pm 15.2$ & 66 & 2.8 & 6.3 \\
\hline
\end{tabular}

Column 1 specifies the treatment, either depletion $(\Delta)$ of Cdk1 or Cdk2, cyclin E (CycE) or cyclin A (CycA). Combed DNAs were from 75-min time points and extracts included a low concentration $(5 \mu \mathrm{M})$ of aphidicolin to block elongation and allow determination of initiation events. The second column presents the \% of input DNA replicated by $75 \mathrm{~min}$ as determined by an independent replication assay (without aphidicolin) in the same experiment. All other data are determined from counting BrdU incorporation events on combed DNAs, as explained in the text. ${ }^{\mathrm{a}}$ Calculated as follows: total length (BrdU + fibres)/total length (BrdU- and BrdU +) fibres $\times 100(\%)$.

${ }^{\mathrm{b}}$ Assuming no clustering of origins.

${ }^{\mathrm{c}}$ Spacing was measured between observed adjacent origins.

${ }^{\mathrm{d}}$ Assignment of origins to clusters based on definition in text.

both enzymes can promote DNA replication might mean that natural variability is tolerated. In favour of this hypothesis, there was also significant variability in residual DNA replication in extracts treated with the Cdk2 inhibitor Nu6102, suggesting that Cdk1 is more or less important in different extracts. Second, when we combine depletion of Cdk2, for example, with inhibition by Nu6102, in an attempt to inhibit whatever residual Cdk2 might remain after depletion, the extract will usually replicate to around $30-40 \%$, whereas on some occasions, Cdk2 depletion alone or Nu6102 inhibition alone might allow only $10 \%$ replication. This again suggests that experimental variability might be a natural outcome of biochemical variability in the system.

One consequence of our data is that Cdk1 and Cdk2 complexes must have different activities towards the genuine substrates involved in DNA replication. For example, reduction of most activity (at least $80 \%$ ) of one or both Cdks causes only a minor effect on DNA replication (which is at most $20 \%$ slower), but complete elimination of Cdk2 complexes alone causes a significant reduction (around 70\%) in DNA replication. If Cdk1 and Cdk2 activities towards the artificial substrate histone $\mathrm{H} 1$ were a genuine reflection of their physiological activities, then considering only total kinase activity present, in the former case $20 \%$ kinase activity would provide $80 \%$ replication efficiency, whereas in the latter case $33 \%$ kinase activity (as Cdk1 has around half the $\mathrm{H} 1$ kinase activity of $\mathrm{Cdk} 2$ at this point) would provide only $30 \%$ efficiency. Indeed, in yeast, different Cdk complexes have different activities towards the genuine substrates for DNA replication (Loog and Morgan, 2005), and it now seems that the same must be true for vertebrate Cdk1cyclin A and Cdk2-cyclin E complexes in Xenopus egg extracts. Nevertheless, one kinase alone is minimally sufficient to promote substantial DNA replication. In the Xenopus extract system, we suggest that both Cdk1 and Cdk2 fulfill a role of 'S-phase Cdk complexes', although they may have different kinetic parameters for S-phase substrates.

We quantify relative Cdk activity (albeit against histone H1) required for DNA replication in Xenopus extracts, and find that only around $1 \%$ of total histone $\mathrm{H} 1$ kinase activity present at M-phase is sufficient for DNA replication. This might also partly account for the apparent difficulty in identifying a Cdk essential for DNA replication in any metazoan system. Furthermore, we provide evidence that in the Xenopus embryonic system, Cdk activity appears to be buffered by replication origin usage. As such, only a minor delay in DNA replication is observed when most Cdk1 or Cdk2 activity is eliminated, and DNA replication is severely compromised only when nearly all Cdk2 (or better still, Cdk2 and Cdk1) is eliminated. Thus, when Cdk levels are low, small variations in remaining Cdk activity have much larger effects on replication efficiency. But even with very low Cdk activity, some origins can still fire. Therefore, in contrast to mitosis onset, where a threshold level of Cdk activity provides a switch-like 'all or nothing' response (Pomerening et al, 2003), this is not true of DNA replication, in Xenopus egg extracts. Whether or not this holds true for somatic cells is a very important question. We further find that when Cdk activity is sufficiently reduced to compromise DNA replication, there is a direct relationship between kinase activity and replication efficiency, which is due to limiting replication origin activation. In other words, at low Cdk activity levels, the probability of origin firing is directly related to the level of Cdk activity. This quantitative relationship also seems to be true for the pre-RC to pre-IC transition, reinforcing the idea that, in embryonic replication in Xenopus, this is the major point at which Cdks control initiation.

Our results lead us to propose a revised quantitative model for Cdk regulation of DNA replication in which finite but very low levels of Cdk activity are required to promote the pre-RC to pre-IC transition and allow activation of a replication origin. While specific G1 Cdk-cyclin complexes may allow highly efficient DNA replication occurring in early development situations, we suggest that this is not an inherent qualitative requirement but a reflection of the probability of activation of individual origins, due to kinetic differences between different Cdk complexes and substrates involved in higher order origin organization. As a consequence, even extremely low Cdk activity resulting from protein depletions or pharmacological inhibitors may still allow some origins to activate. This might have important consequences for the treatment of cancer with Cdk inhibitors. G1/S-phase-controlling 
Table II Molecular combing data upon Cdk1 or Cdk2 depletion in the absence of aphidicolin

\begin{tabular}{|c|c|c|c|c|c|c|c|c|c|c|}
\hline & $\begin{array}{c}\% \text { DNA } \\
\text { replicated at } \\
75 \text { min }\left(\alpha^{-3}{ }^{33} \mathrm{P}\right. \\
\text { dCTP inc.) }\end{array}$ & $\begin{array}{c}\mathrm{kb} \mathrm{BrdU} / \mathrm{Mb} \\
\text { total } 75 \mathrm{~min} \\
\text { (combing) }\end{array}$ & $\begin{array}{c}\% \text { BrdU + } \\
\text { fibres } \\
75 \mathrm{~min}\end{array}$ & $\begin{array}{c}\text { Mean track } \\
\text { size } \pm \text { s.d. } \\
75 \text { min }\end{array}$ & $\begin{array}{c}\text { Mean gap } \\
\text { size } \pm \text { s.d. } \\
75 \text { min }\end{array}$ & $\begin{array}{c}\% \text { DNA repli- } \\
\text { cated at } \\
90 \text { min }\left(\alpha^{-3}{ }^{33} \mathrm{P}\right. \\
\text { dCTP inc. })\end{array}$ & $\begin{array}{c}\mathrm{kb} \text { BrdU/ } \\
\text { Mb total } \\
90 \text { min }\end{array}$ & $\begin{array}{c}\% \text { BrdU + } \\
\text { fibres } \\
90 \text { min }\end{array}$ & $\begin{array}{c}\text { Mean track } \\
\text { size } \pm \text { s.d. } \\
90 \text { min }\end{array}$ & $\begin{array}{c}\text { Mean gap } \\
\text { size } \pm \text { s.d. } \\
90 \text { min }\end{array}$ \\
\hline Mock & 24 & 249 & 66 & $12.4 \pm$ & $19.4 \pm 22.1$ & 44 & 405 & 77 & 15.8 & $13.6 \pm 12.3$ \\
\hline$\Delta \mathrm{Cdk} 1$ & 5.5 & 77 & 38 & $11.4 \pm 10.1$ & $30.5 \pm 3$ & 9.4 & 149 & 56 & 3.9 & $34.9 \pm 37.9$ \\
\hline$\Delta \mathrm{Cdk} 2$ & 2.8 & 78 & 30 & $9.3 \pm 4.4$ & $25.1 \pm 23.8$ & 4.6 & 90 & 41 & $10.8 \pm 5.5$ & $26.7 \pm 32.4$ \\
\hline
\end{tabular}

Column 1 specifies the treatment; columns 2-6 show data from the 75-min time point; columns 7-11 show data from the 90-min time point. Columns 2, 3, 7 and 8 show quantification of replication either by an independent replication assay (columns 2 and 7) or by determining total BrdU incorporation per $\mathrm{Mb}$ (columns 3 and 8). Columns 4 and 9 show the percentage of fibres between 90 and $110 \mathrm{~kb}$ that show any BrdU incorporation, for each situation. Columns 5 and 10 present the mean lengths of measured tracks, and 6 and 11 present the mean lengths of non-BrdU-labelled DNA between the tracks (gaps).
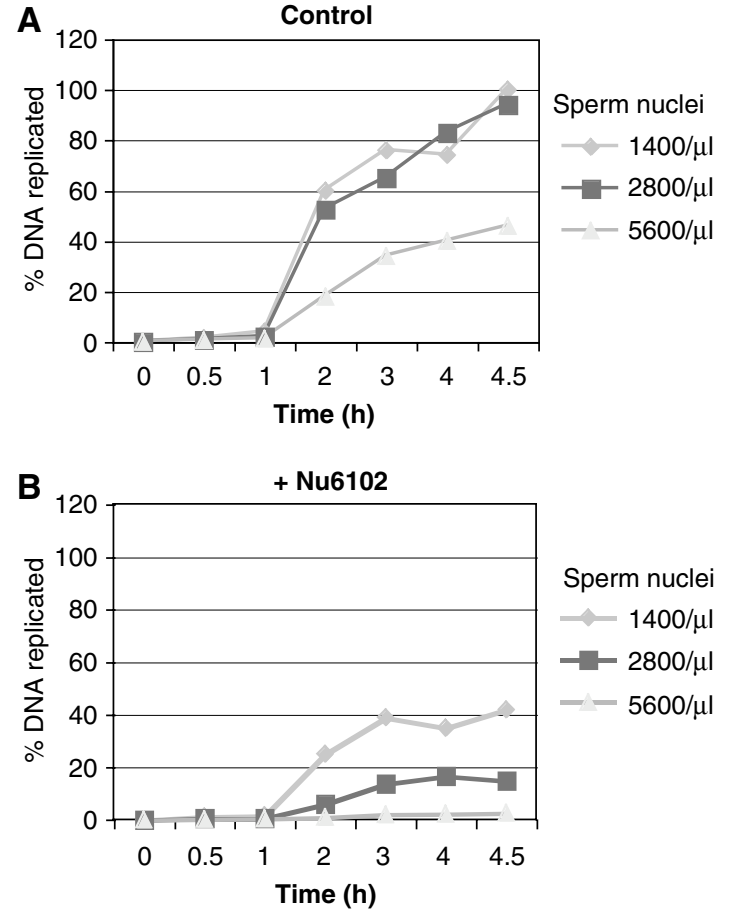

Figure 7 Titrating limiting Cdk activity with increasing nuclei concentration limits replication efficiency accordingly. Replication time courses at the indicated concentrations of sperm nuclei in control (A) or Nu6102-treated (B) extracts. A full-colour version of this figure is available at The EMBO Journal Online.

Cdks are attractive anticancer targets, and many small-molecule Cdk inhibitors are currently in development with a view to cancer chemotherapy (Senderowicz, 2003). However, inefficient DNA replication, due to low origin usage, might lead to increased genomic instability (Spruck et al, 1999), especially if cells retain some capacity to undergo mitosis. As such, inhibiting Cdk activity controlling DNA replication might even be counterproductive and accelerate the process of carcinogenesis.

\section{Materials and methods}

\section{Xenopus egg extracts and replication reactions}

Interphase egg extracts (IEEs) were prepared as essentially as described (Blow and Laskey, 1986), and details are present in Supplementary data (S13). In one experiment, $100 \mu \mathrm{g} / \mathrm{ml}$ cycloheximide was added during extract preparation. To measure relative Cdk activities in mitotic versus interphase eggs, extracts were prepared from five eggs of the same pool arrested in metaphase or released into interphase by calcimycin treatment. Eggs were crushed by pipetting in $10 \mu \mathrm{l}$ per egg of, respectively, XB- (CSF) $(\mathrm{XB}+5 \mathrm{mM}$ ethylene glycol tetraacetic acid (EGTA)) or XB, with protease and phosphatase $(50 \mathrm{mM} \mathrm{NaF}, 5 \mathrm{mM} \mathrm{NaPPi}, 10 \mathrm{mM} \beta$ glycerophosphate) inhibitors, and spun ( $\left.1 \mathrm{~min}, 6000 \mathrm{~g}, 4^{\circ} \mathrm{C}\right)$. A $2-\mu \mathrm{l}$ volume of this extract was removed for western blot, $2 \mu$ l for $\mathrm{H} 1$ kinase activity and $20 \mu \mathrm{l}$ for Cdk1 and Cdk2 immunoprecipitations and kinase assays. For replication assays, extract aliquots were thawed, sperm nuclei were added to a final concentration of $1400 / \mu \mathrm{l}$, unless stated otherwise, and $0.2 \mu \mathrm{Ci} / \mu \mathrm{l} \alpha^{33} \mathrm{P}$-labelled dCTP, energy mix (Supplementary data (S13)) and cycloheximide $(100 \mu \mathrm{g} / \mathrm{ml})$ were added. Where indicated, $100 \mu \mathrm{M}(1: 100$ dilution $)$ Nu6102 (EMD Biosciences) or dimethylsulphoxide (DMSO) solvent only was added. For rescue experiments, recombinant human Cdk1/cycE, Cdk2/cycE or Cdk2/cycA complexes (ProQinase $\mathrm{GmbH}$ ), at a final concentration of $30 \mathrm{nM}$ for Cdk1 and $120 \mathrm{nM}$ for Cdk2 (1:50 dilution), were added to Cdk2- or cyclin E-depleted extracts. DNA synthesis was measured from aliquots taken at the indicated time points, spotted onto glass fibre filters, precipitated in cold 5\% trichloroacetic acid (TCA), 1\% pyrophosphate, washed three times in 5\% TCA, dried and counted by scintillography. Recombinant Xenopus Cdk-cyclin complexes were purified from bacteria bicistronically expressing glutathione-S-transferase (GST) Xenopus Cdks and GST-CAK, and mixed with bacterially expressed Xenopus cyclins. A detailed protocol is available on request.

\section{Immunodepletion and immunoprecipitation}

A 20- $\mu$ l volume of packed protein G-Sepharose (Roche) beads was incubated with $40 \mu \mathrm{l}$ of preimmune (mock), anti-XCdk1, XCdk2, $\mathrm{XCycE} 1$ or XCycA1 serum at $4^{\circ} \mathrm{C}$ for $2 \mathrm{~h}$, washed three times in phosphate-buffered saline (PBS) and twice in XB. Buffer was removed by centrifugation and blotting with Whatman paper. Beads were resuspended in $50 \mu \mathrm{l}$ of IEEs, incubated on ice for $40 \mathrm{~min}$ with agitation and pelleted by spinning at $2000 \mathrm{~g}$ for $30 \mathrm{~s}$, and the supernatant removed and used for further experiments. Two rounds of depletions were performed unless otherwise stated. A 1- $\mu$ l volume was taken for western blot control of depletion.

\section{Kinase assays}

Beads from immunoprecipitations (from $10 \mu$ l extract) were washed twice in $25 \mathrm{mM}$ Tris, pH 7.5, $150 \mathrm{mM} \mathrm{NaCl}, 0.1 \%$ Triton X-100, $1 \mathrm{mM}$ ethylenediamine tetraacetic acid, $1 \mathrm{mM}$ EGTA, $1 \mathrm{mM}$ dithiothreitol (DTT) and protease inhibitors, once in $25 \mathrm{mM}$ Tris, $\mathrm{pH} 7.5$, $10 \mathrm{mM} \mathrm{MgCl}_{2}, 1 \mathrm{mM}$ DTT and resuspended in $20 \mu \mathrm{l}$ kinase buffer (50 mM HEPES, pH 7.6, $10 \mathrm{mM} \mathrm{MgCl} 2,1 \mathrm{mM}$ DTT, $0.02 \%$ Triton X$100,100 \mu \mathrm{g} / \mathrm{ml}$ of histone $\mathrm{H} 1,50 \mu \mathrm{M}$ ATP, $0.1 \mu \mathrm{Ci} / \mu \mathrm{l} \gamma^{33}$ P-labelled ATP). Reactions were carried out for $20 \mathrm{~min}$ at $25^{\circ} \mathrm{C}$, stopped by adding Laemmli buffer, analysed by sodium dodecyl sulphatepolyacrylamide gel electrophoresis and quantified by phosphorimager. Alternatively, the reaction was stopped by spotting onto $\mathrm{p} 81$ phosphocellulose filters and placing into $10 \mathrm{ml}$ per filter $1 \%$ orthophosphoric acid, followed by two washes, drying and scintillography.

\section{Immunofluorescence}

For immunofluorescence, $10 \mu \mathrm{l}$ per time point of IEEs containing sperm nuclei, $20 \mu \mathrm{M}$ biotin-dUTP and either Nu6102 (100 $\mu \mathrm{M}$ final) or DMSO as a control were diluted in $100 \mu \mathrm{l}$ of XB. Nuclei were centrifuged at 3000 r.p.m. at $4^{\circ} \mathrm{C}$ for $10 \mathrm{~min}$ through $0.7 \mathrm{M}$ sucrose/ 
$\mathrm{XB}$ onto glass coverslips. After rinsing in $\mathrm{XB}$, they were fixed in $3.7 \%$ formaldehyde/XB for $15 \mathrm{~min}$ at $25^{\circ} \mathrm{C}$, rinsed in PBS and postfixed in $-20^{\circ} \mathrm{C}$ ethanol for $5 \mathrm{~min}$, rehydrated in PBS $/ 0.05 \%$ Triton-X 100 for 10 min and blocked in PBS/0.05\% Triton-X 100/2\% bovine serum albumin for $1 \mathrm{~h}$. Streptavidin-Texas Red was used according to manufacturer's instructions. DNA was stained with $1 \mu \mathrm{g} / \mathrm{ml}$ Hoechst 33258. Images were taken with an upright microscope using Metamorph 6.2.6. software (Molecular Devices), using constant exposure times for each filter setting.

\section{Chromatin isolation}

For chromatin fractions, at each time point, $25 \mu \mathrm{l}$ of IEEs with sperm nuclei (or not: -DNA control) was diluted $20 \times$ in chromatin preparation buffer (CPB) $(50 \mathrm{mM} \mathrm{KCl,} 20 \mathrm{mM}$ HEPES, pH 7.6, $2 \%$ sucrose, $5 \mathrm{mM} \mathrm{MgCl}_{2}$ ) with protease inhibitors, layered onto $1 \mathrm{ml}$ sucrose cushion (0.7 M sucrose in $\mathrm{CPB}$ ) and centrifuged at $4^{\circ} \mathrm{C}$ for $5 \mathrm{~min}$ at $6000 \mathrm{~g}$. The pellet was resuspended in $50 \mu \mathrm{l} \mathrm{CPB}$ containing $0.2 \%$ Triton X-100, recentrifuged, recovered in $20 \mu \mathrm{l}$ Laemmli buffer and analysed by western blotting.

\section{Antibodies}

Antibodies used were as follows: polyclonals: XCdk1 C-terminal peptide (gift from T Lorca); XCdk2 C-terminal peptide and Xcyclin E1 (whole protein) (gifts from C Bonne-Andrea); Xcyclin A1 (whole

\section{References}

Aleem E, Kiyokawa H, Kaldis P (2005) Cdc2-cyclin E complexes regulate the G1/S phase transition. Nat Cell Biol 7: 831-836

Berthet C, Aleem E, Coppola V, Tessarollo L, Kaldis P (2003) Cdk2 knockout mice are viable. Curr Biol 13: 1775-1785

Blow JJ, Laskey RA (1986) Initiation of DNA replication in nuclei and purified DNA by a cell-free extract of Xenopus eggs. Cell 47: $577-587$

Blow JJ, Nurse P (1990) A cdc2-like protein is involved in the initiation of DNA replication in Xenopus egg extracts. Cell 62: 855-862

Blow JJ, Gillespie PJ, Francis D, Jackson DA (2001) Replication origins in Xenopus egg extract are 5-15 kilobases apart and are activated in clusters that fire at different times. J Cell Biol 152: $15-25$

Chevalier S, Tassan JP, Cox R, Philippe M, Ford C (1995) Both cdc2 and cdk2 promote $\mathrm{S}$ phase initiation in Xenopus egg extracts. J Cell Sci 108 (Part 5): 1831-1841

Coverley D, Laman H, Laskey RA (2002) Distinct roles for cyclins E and A during DNA replication complex assembly and activation. Nat Cell Biol 4: 523-528

Davies TG, Bentley J, Arris CE, Boyle FT, Curtin NJ, Endicott JA, Gibson AE, Golding BT, Griffin RJ, Hardcastle IR, Jewsbury P, Johnson LN, Mesguiche V, Newell DR, Noble ME, Tucker JA, Wang L, Whitfield HJ (2002) Structure-based design of a potent purine-based cyclin-dependent kinase inhibitor. Nat Struct Biol 9: 745-749

Donaldson AD, Raghuraman MK, Friedman KL, Cross FR, Brewer BJ, Fangman WL (1998) CLB5-dependent activation of late replication origins in S. cerevisiae. Mol Cell 2: 173-182

Fang F, Newport JW (1991) Evidence that the G1-S and G2-M transitions are controlled by different cdc2 proteins in higher eukaryotes. Cell 66: 731-742

Fisher DL, Nurse P (1996) A single fission yeast mitotic cyclin B p34cdc2 kinase promotes both S-phase and mitosis in the absence of G1 cyclins. EMBO J 15: 850-860

Furstenthal L, Kaiser BK, Swanson C, Jackson PK (2001) Cyclin E uses Cdc6 as a chromatin-associated receptor required for DNA replication. J Cell Biol 152: 1267-1278

Geng Y, Lee YM, Welcker M, Swanger J, Zagozdzon A, Winer JD, Roberts JM, Kaldis P, Clurman BE, Sicinski P (2007) Kinaseindependent function of cyclin E. Mol Cell 25: 127-139

Geng Y, Yu Q, Sicinska E, Das M, Schneider JE, Bhattacharya S, Rideout WM, Bronson RT, Gardner H, Sicinski P (2003) Cyclin E ablation in the mouse. Cell 114: 431-443

Hashimoto Y, Takisawa H (2003) Xenopus Cut5 is essential for a CDK-dependent process in the initiation of DNA replication. EMBO J 22: 2526-2535 protein); XCdc45 (gift from $\mathrm{H}$ Takisawa); geminin, Cdt1, Cdc6, MCM4 (whole proteins); monoclonals: Xcyclin A1 (Abcam); MCM7, MCM5, PCNA (Labvision); PSTAIR (Sigma).

\section{DNA combing}

Molecular combing was performed as previously described (Michalet et al, 1997; Lemaitre et al, 2005).

\section{Supplementary data}

Supplementary data are available at The EMBO Journal Online (http://www.embojournal.org).

\section{Acknowledgements}

This work was funded by ARC grants 3278 to DF and 3155 to JML, FRM start up grants and Inserm Avenir grants to DF and JML; LK was funded by the EC consortium Mitocheck and an Inserm 1 year postdoc; EC by a grant from Inserm and the Région Languedoc Roussillon; EB by a grant from the Ministère de la Recheche et la Technologie. We thank Cécile Boyer of the Molecular Combing facility at the IGMM, Montpellier, for providing slides, and to Philippe Jay and Vjeko Dulic for critical discussion.

Herrick J, Stanislawski P, Hyrien O, Bensimon A (2000) Replication fork density increases during DNA synthesis in $X$. laevis egg extracts. J Mol Biol 300: 1133-1142

Hyrien O, Maric C, Mechali M (1995) Transition in specification of embryonic metazoan DNA replication origins. Science 270: 994-997

Hochegger H, Dejsuphong D, Sonoda E, Saberi A, Rajendra E, Kirk J, Hunt T, Takeda S (2007) An essential role for Cdk1 in S phase control is revealed via chemical genetics in vertebrate cells. J Cell Biol 178: 257-268

Jackson PK, Chevalier S, Philippe M, Kirschner MW (1995) Early events in DNA replication require cyclin $\mathrm{E}$ and are blocked by p21CIP1. J Cell Biol 130: 755-769

Jacobs HW, Keidel E, Lehner CF (2001) A complex degradation signal in cyclin A required for G1 arrest, and a C-terminal region for mitosis. EMBO J 20: 2376-2386

Jares P, Blow JJ (2000) Xenopus cdc7 function is dependent on licensing but not on XORC, XCdc6, or CDK activity and is required for XCdc45 loading. Genes Dev 14: 1528-1540

Knoblich JA, Sauer K, Jones L, Richardson H, Saint R, Lehner CF (1994) Cyclin E controls S phase progression and its downregulation during Drosophila embryogenesis is required for the arrest of cell proliferation. Cell 77: 107-120

Knockaert M, Greengard P, Meijer L (2002) Pharmacological inhibitors of cyclin-dependent kinases. Trends Pharmacol Sci 23: 417-425

Kobayashi H, Golsteyn R, Poon R, Stewart E, Gannon J, Minshull J, Smith R, Hunt T (1991) Cyclins and their partners during Xenopus oocyte maturation. Cold Spring Harb Symp Quant Biol 56: 437-447

Lemaitre JM, Danis E, Pasero P, Vassetzky Y, Mechali M (2005) Mitotic remodeling of the replicon and chromosome structure. Cell 123: 787-801

Loog M, Morgan DO (2005) Cyclin specificity in the phosphorylation of cyclin-dependent kinase substrates. Nature 434: 104-108

Lucas I, Chevrier-Miller M, Sogo JM, Hyrien O (2000) Mechanisms ensuring rapid and complete DNA replication despite random initiation in Xenopus early embryos. J Mol Biol 296: 769-786

Luciani MG, Oehlmann M, Blow JJ (2004) Characterization of a novel ATR-dependent, Chk1-independent, intra-S-phase checkpoint that suppresses initiation of replication in Xenopus. J Cell Sci 117: 6019-6030

Marheineke K, Hyrien O (2001) Aphidicolin triggers a block to replication origin firing in Xenopus egg extracts. $\mathrm{J}$ Biol Chem 276: $17092-17100$

Marheineke K, Hyrien O (2004) Control of replication origin density and firing time in Xenopus egg extracts: role of a caffeine-sensitive, ATR-dependent checkpoint. J Biol Chem 279: 28071-28081 
Michalet X, Ekong R, Fougerousse F, Rousseaux S, Schurra C, Hornigold N, van Slegtenhorst M, Wolfe J, Povey S, Beckmann JS, Bensimon A (1997) Dynamic molecular combing: stretching the whole human genome for high-resolution studies. Science 277: $1518-1523$

Moore JD, Kirk JA, Hunt T (2003) Unmasking the S-phase-promoting potential of cyclin B1. Science 300: $987-990$

Moore JD, Kornbluth S, Hunt T (2002) Identification of the nuclear localization signal in Xenopus cyclin $\mathrm{E}$ and analysis of its role in replication and mitosis. Mol Biol Cell 13: 4388-4400

Moreau JL, Marques F, Barakat A, Schatt P, Lozano JC, Peaucellier G, Picard A, Geneviere AM (1998) Cdk2 activity is dispensable for the onset of DNA replication during the first mitotic cycles of the sea urchin early embryo. Dev Biol 200: $182-197$

Nurse P (1990) Universal control mechanism regulating onset of Mphase. Nature 344: 503-508

Ortega S, Prieto I, Odajima J, Martin A, Dubus P, Sotillo R, Barbero JL, Malumbres M, Barbacid M (2003) Cyclin-dependent kinase 2 is essential for meiosis but not for mitotic cell division in mice. Nat Genet 35: 25-31

Parisi T, Beck AR, Rougier N, McNeil T, Lucian L, Werb Z, Amati B (2003) Cyclins E1 and E2 are required for endoreplication in placental trophoblast giant cells. EMBO $J$ 22: 4794-4803
Pomerening JR, Sontag ED, Ferrell Jr JE (2003) Building a cell cycle oscillator: hysteresis and bistability in the activation of Cdc2. Nat Cell Biol 5: 346-351

Santamaria D, Barrière C, Cerqueira A, Hunt S, Tardy C, Newton K, Cáceres J, Dubus P, Malumbres M, Barbacid M (2007) Cdk1 is sufficient to drive the mammalian cell cycle. Nature 448: 6046-6050

Schnackenberg BJ, Palazzo RE, Marzluff WF (2007) Cyclin E/Cdk2 is required for sperm maturation, but not DNA replication, in early sea urchin embryos. Genesis 45: 282-291

Senderowicz AM (2003) Small-molecule cyclin-dependent kinase modulators. Oncogene 22: 6609-6620

Shechter D, Costanzo V, Gautier J (2004) ATR and ATM regulate the timing of DNA replication origin firing. Nat Cell Biol 6: 648-655

Spruck CH, Won KA, Reed SI (1999) Deregulated cyclin E induces chromosome instability. Nature 401: 297-300

Strausfeld UP, Howell M, Descombes P, Chevalier S, Rempel RE, Adamczewski J, Maller JL, Hunt T, Blow JJ (1996) Both cyclin A and cyclin E have S-phase promoting (SPF) activity in Xenopus egg extracts. J Cell Sci 109: 1555-1563

Tetsu O, McCormick F (2003) Proliferation of cancer cells despite CDK2 inhibition. Cancer Cell 3: 233-245

Zou L, Stillman B (1998) Formation of a preinitiation complex by S-phase cyclin CDK-dependent loading of Cdc45p onto chromatin. Science 280: 593-596 